\title{
The DERHT Method Application in Orthodontic Practice
}

\section{Dr. Mhd. Azhar Ibrahim Kharsa}

Senior Specialist Orthodontist, King Fahad Hospital-Madinah, Saudi Arabia. Scientist Member of American

Society for Laser Medicine and Surgery, Saudi Arabia. Member of American Association of Orthodontists

*Corresponding Author: Dr. Mhd. Azhar Ibrahim Kharsa, Senior Specialist Orthodontist, King Fahad HospitalMadinah, Saudi Arabia.

\section{Abstract}

Teeth movement depends on forces which move teeth indirectly by stimulating the cellular activity in the surrounding periodontal ligament and alveolar bone. It is recommended that such structures of periodontal ligaments and alveolar bone be stimulated by light and continuous forces; as such forces are biologic avoiding the secondary side effects of roots and bone resorption. NiTi wires have that ability to move the teeth in a fast and healthy manner delivering a low and continuous level of force. However, the dilemma of NiTi wires was in their difficulty to bend properly without losing their properties of shape memory and superelasticity.

Nonetheless, several ways and approaches were attempted to surmount the aforementioned difficulty, bend NiTi wires and simultaneously keep their superelastic properties, some of these ways and approaches are: DERHT Method, DHAHT Method "Direct Hot Air Heating Treatment", Robot Machine Bender and hot salt bath with proper molds.

Keywords: Shape Memory Alloys "SMA", Nickel Titanium, DERHT, Superelasticity, Springiness, Bending NiTi wires, Lingual Orthodontics, dental movement.

\section{INTRODUCTION}

In this article the authors show the clinical application of DERHT technique which permits the orthodontist to handle the "shape memory alloys wires", especially the Nickel Titanium wires without changing their superelastic and shape memory properties.

The word DERHT is an acronym of the following words: Direct Electric Resistance Heat Treatment.

Miura et al. developed the first machine that utilized the aforementioned technique at 1988. (Figure 1)

The aforementioned machine was fabricated under the name of ARCHMATE by GAC at 1988, but it wasn't popular. This machine produces an electric current needed to shape setting of the NiTi wires. The energy is provided by the electric current raises the temperature of the targeted wire, heating it until determined temperature where the wire becomes shapeable, using simple managements manually with a pair of pliers connected to the machine at the side of the dental chair in brief seconds, extraorally.

The machine delivers the energy to the wire to be modified through two independent pliers: the first one is connected to the positive pole of the electric machine, whereas the other plier is connected to the negative pole. With both pliers holding the targeted wire, the electricity is transmitted until the wire reaches the shapeable phase appearing with a golden colored surface, what enables wire bending at that moment for creating whatever orthodontist needs of coils, archwires, lever arms and springs.

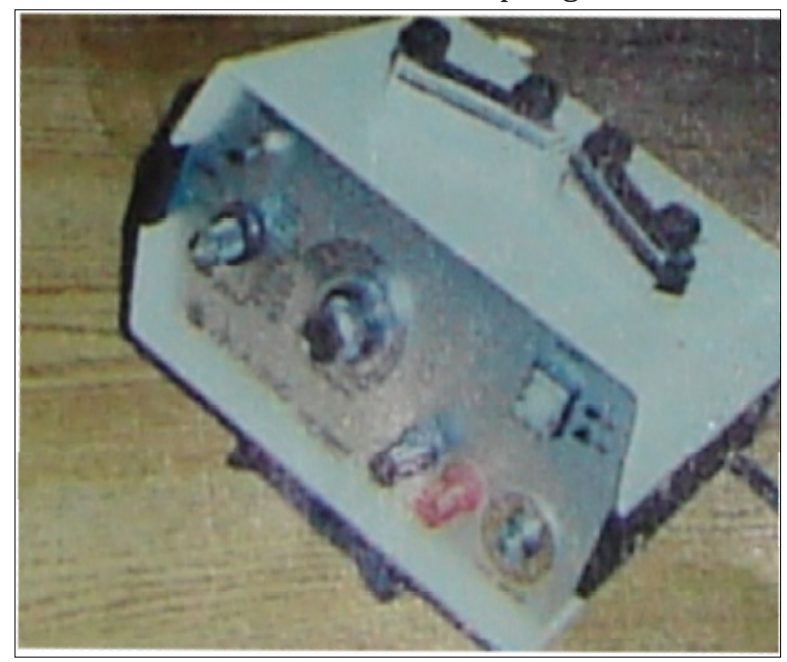

Fig1. The old machine ARCHMATE fabricated by GAC to apply the DERHT Method developed by Miura in 1988 (picture taken from Orto Latina, Vol 1 №1, 1999) 
In brief, this technique is worthwhile to be studied, developed and applied as it helps orthodontist in getting advantage of the superelastic properties of NiTi alloys to apply low and continuous forces which ensure the physiologic conditions for orthodontic movement along the entire orthodontic treatment since the very beginning until the finishing stage.

\section{Materials AND Methods}

In the beginning of the XXI century orthodontics has reach a high technical development thanks to the big technologic jump of the world in whole.

There is clear clinical evidence of the good results in the treatments thanks to the application of low and continuous forces. The availability of the memory shape alloys "as NiTi with high superelasticity" has made possible to move the teeth within the physiological boundaries at the cellular level of the bone surrounding the teeth. No other alloy can move the teeth softly but persistently as NiTi alloys. The treatments are executed in shorter times, simultaneously avoiding the usual secondary sideeffects seen in other alloys like the bone loss and the root apical resorption.

However, the use of the memory shape alloys has not been utilized as frequent as it should be and clinicians are not aware of all capabilities that the wires have. Perhaps as the NiTi wires are not liable to be handled with simple pliers as the other alloys are. As a result clinicians have become dependant on the factories who provide the wires according to their standards and symmetrical shapes without the freedom to modify the NiTi wires.
Nonetheless, a technique was developed by Miura et al. 20 years ago to get control of the bends performed on Shape Memory Alloys wires. Unfortunately, the aforementioned technique was forgotten and the "SMA" wires had carried on unbendable in orthodontic clinics and offices for an additional couple of decades.

The resurgence of the lingual orthodontics "where it needs special bends for the most efficient orthodontic arch" requires that clinicians be encouraged to get special skills in achieving the bends to reach the most efficient wire of lingual orthodontics. Simultaneously, the NiTi wires are of paramount importance in lingual technique where less force values with more elastic properties are required. Consequently, the DERHT method appears to be a solution for the lingual orthodontic technique to achieve a magnificent outcomes and standards that resemble the conventional labial technique.

To apply the DERHT method a machine with electric potentiometers is needed for controlling all the aspects of the electrical current: the voltage, the amperage, the time and whether to deliver the electricity as a pulse or a continuous current. The highest voltage does not surpass the 5 Volts, the frequency is supposed to be in- between 0 and 20 hertz and the intensity is inbetween 0 and 20 amperes. The machine must have two poles to connect the cables to the tools consisted of two pliers. The pliers are connected independently to the electric poles, as the first plier is connected to the positive pole, whereas the other plier is connected to the negative one (figure 2). This technique insures the required bending of a NiTi wire without losing the physical beneficial properties of such a wire, like the superelasticity and the shape memory when the wire is thermally sensitive.

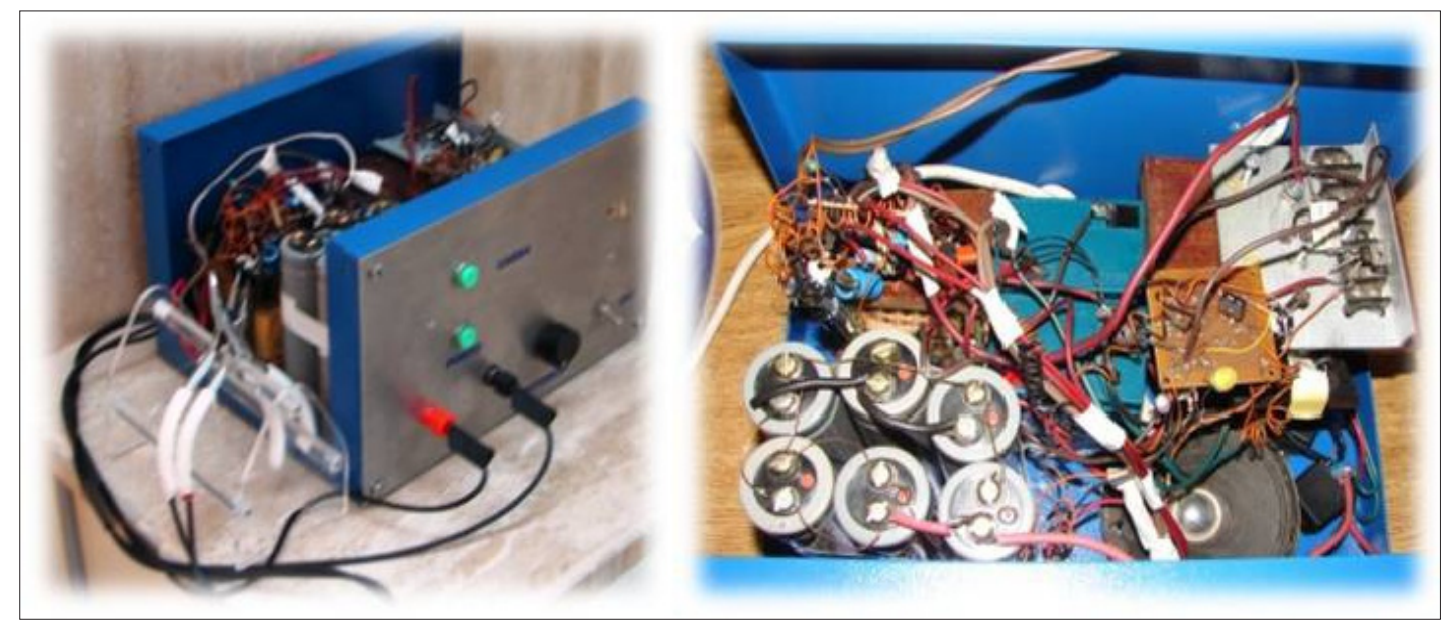

Fig2. The handcrafted dual machine for tacking welding and for bending process. 
As it is known in physics, when an electric current goes around a wire, the result of the current plus wire resistance is heat. While the electric current goes around the wire, its temperature rises until being incandescent (figure 3).

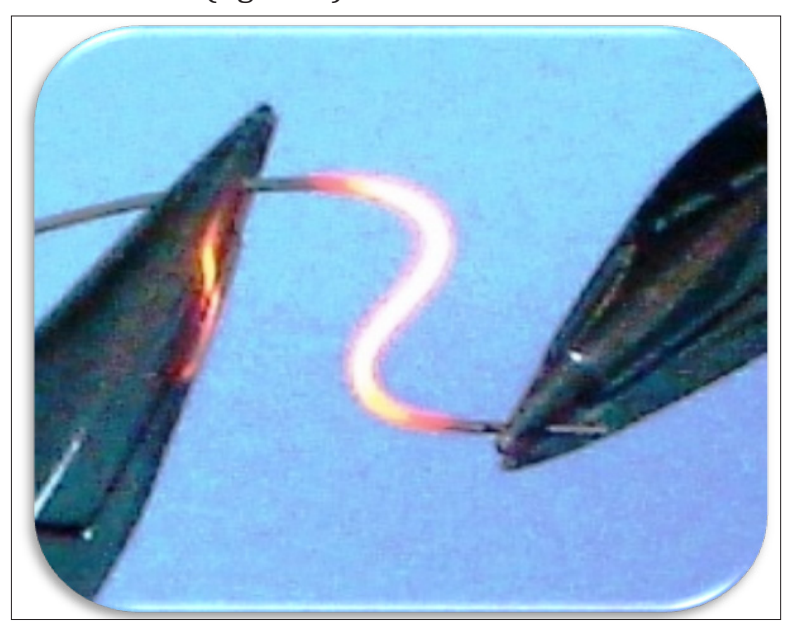

Fig3. Shows how wire is held during reshaping process when the wire is heated using the DERHT method.

The application of this conception into orthodontic practice is by discerning the appropriate point on such a sequence, when wire reaches the correct temperature that enables the practitioner to reshape the wire using his pair of pliers (figure4).

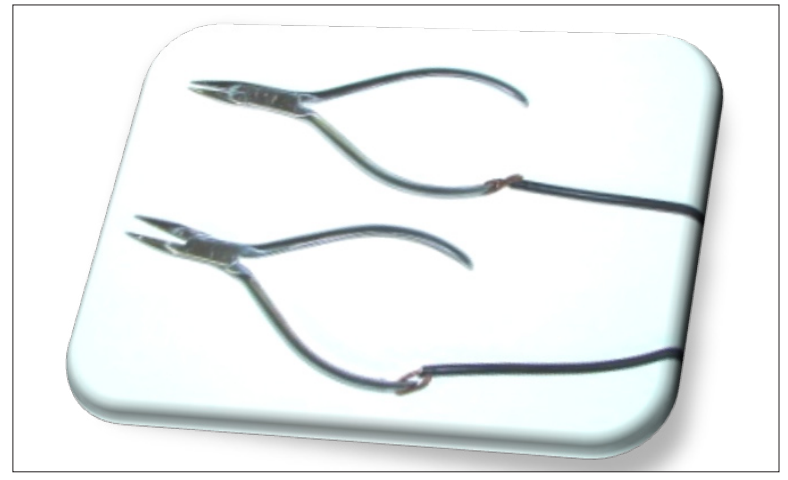

Fig4. The pliers are connected to the poles of DERHT device, via electric wires.

On the other hand, it is crucial that practitioner be aware of the required time for performance of the aimed reshaping, as to prevent any potential defect on the targeted wire.

The practical benefit for DERHT method is in getting advantage of the high superelasticity of NiTi wires, insertion of such a superelastic alloy in all treatment phases and obtaining biologic low and continuous forces, what helps in avoiding the potential side-effects that seen when stiff forces applied like bone loss and apical resorption.
The wire, the pair of pliers and the current form an electrical circuit that is referred to sometimes as Modulation Circuit.

This circuit requires that one plier has to be connected to the positive pole, with another counterpart plier connected to the negative pole. (Figure 4)

By handling both pliers, attached to the both poles, with current going around, practitioner can reshape the NiTi wire when it reaches the correct temperature. (Figure 5)

The amount of the electric energy need for reshaping of a wire depends on its cross- section and the length of the wire between the points of electrodes application.

Despite of the theoretical need to adjust the output activity each time (current intensity and frequency), practitioner is capable to follow two parameters that assist orthodontist in controlling the required time per supposed current intensity and frequency values, what alleviates the need to every time adjustment of the output activities.

These parameters are the wire color, and the wire tact or "shapeable status".

Firstly, the color is a good parameter for the practitioner, as the wire becomes shapeable when the current energy going around it, turns it into golden colored (figure 5).

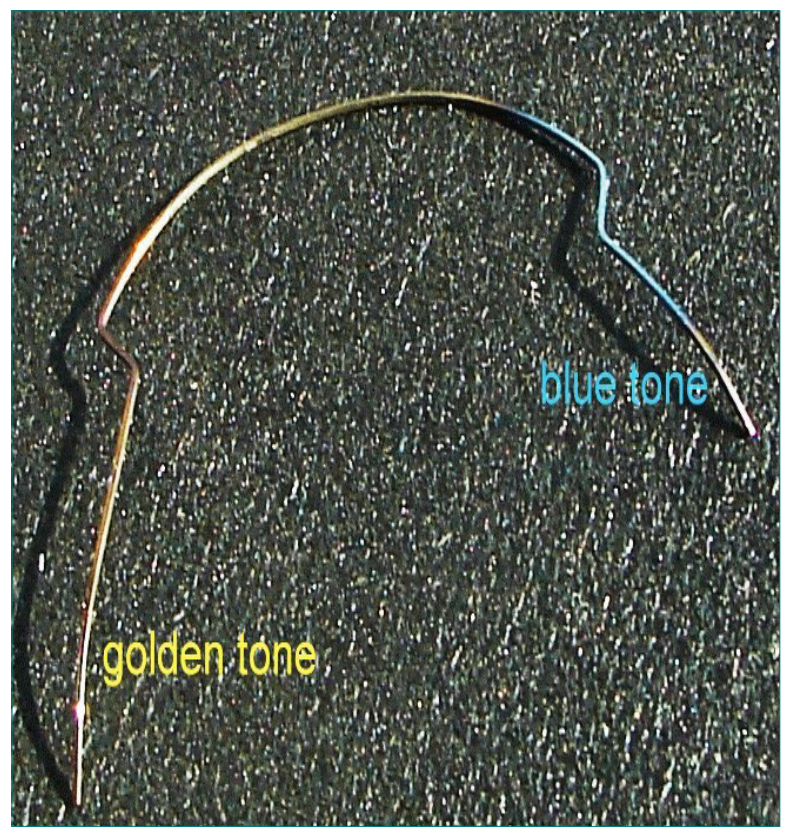

Fig5. The golden color of the wire indicates that it is the correct moment for wire reshaping. 
The DERHT Method Application in Orthodontic Practice

Secondly, when the wire reaches the correct shaping point, the orthodontist feels the sense of loose without power

Nonetheless, it is recommended that practitioner take care of the color parameter carefully, as for instance the blue or violet colors indicate that the wire is not useful for orthodontic utilization, whereas darker than golden color indicates that wire starts burning (figure 6).

In brief, the energy depends on the wire cross section and length, consequently the bigger the wire

is, the higher energy required.

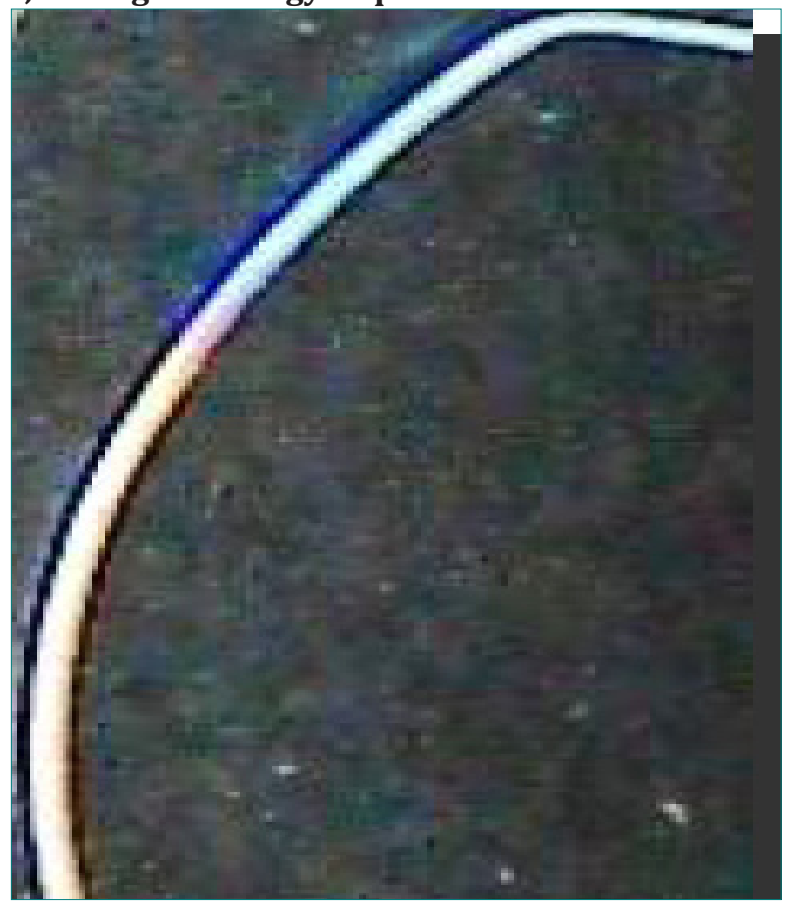

Fig6. The darkened colors indicate that wire starts burning.

\section{DiscusSion}

The DERHT Method is of paramount importance in helping orthodontist in daily practice, as it enables practitioner to not be dependant on the companies which make the commercial NiTi arch wires that lack the formability in orthodontic offices in general, without following such a method.

Besides, DERHT Method enables practitioner to make his/her own springs, sectional archwires, personalized archwires (figure 7) and to fix and reactivate the in use wires (figure 8), and coils (figure 9).

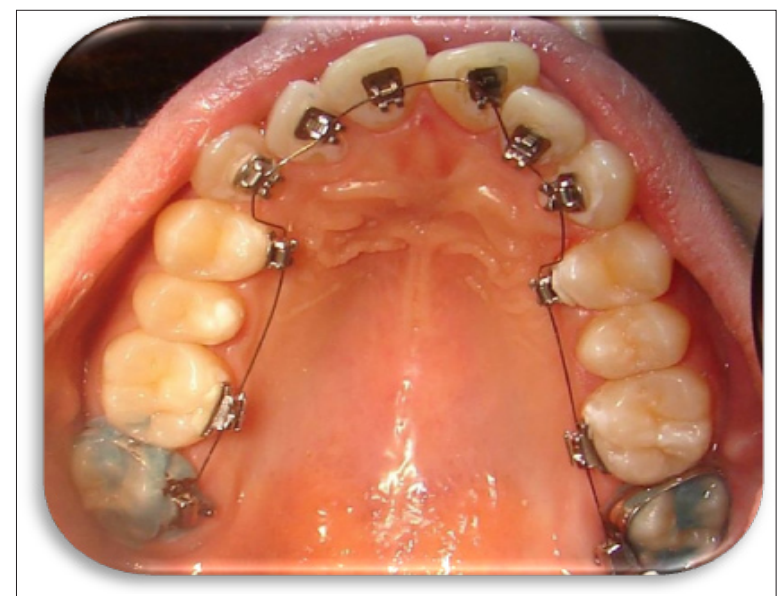

Fig7. A personalized archwire utilized and installed in lingual orthodontics

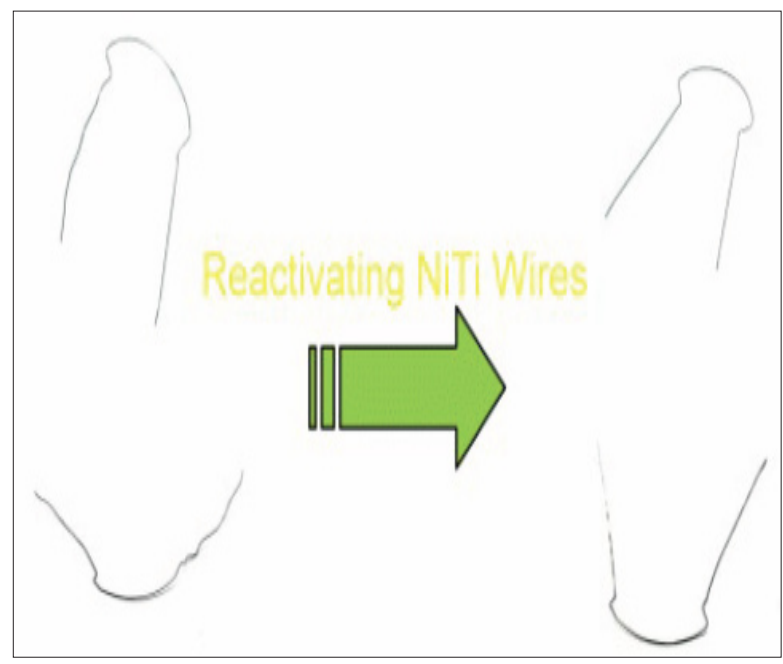

Fig8. The archwire bending and reactivation of the distorted wires in the daily practice.

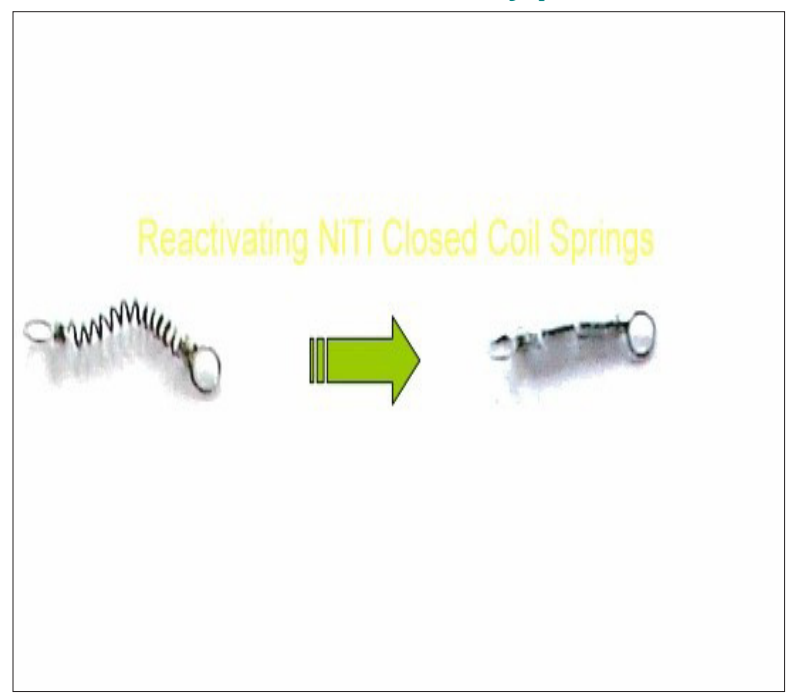

Fig9. The reactivation of the in use coil springs in the usual orthodontic practice. 
The clinical application of DERHT method helps orthodontist in creation whatever needed of springs, in the preferred sizes and shapes that get along with every case, per se.

The benefit of application of this technique into orthodontic practice is in creation the necessary wires, peculiar archwires, traction auxiliaries and force modules "in general" that utilize NiTi wires, getting advantage of NiTi alloy properties as the superelasticity or the capability of deliver soft and continuous springback property (figure 10).

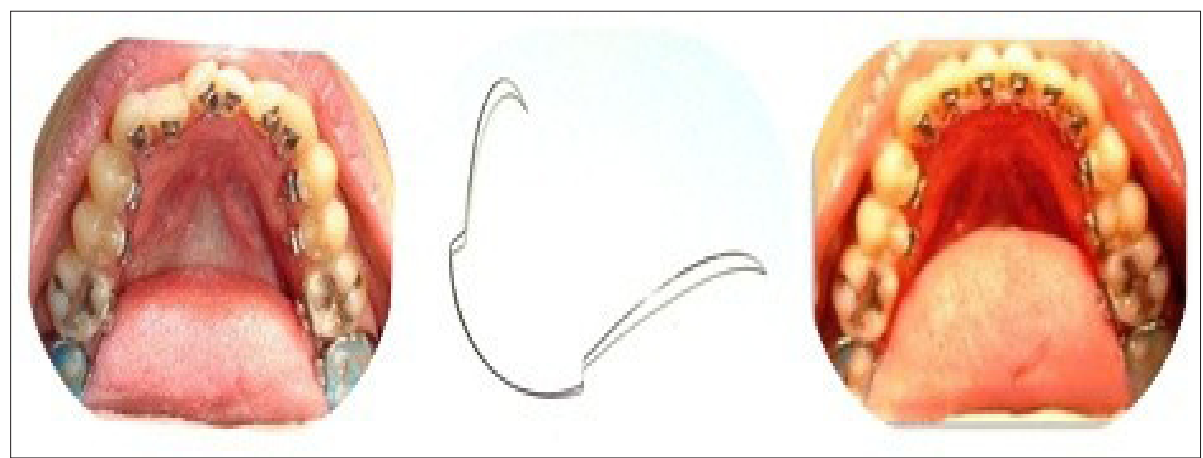

Fig10. A personalized NiTi lingual archwire with basic insets and reverse curve made following the DERHT method

\section{Derht Method in Lingual Technique}

The advent of lingual technique into daily orthodontic practice formed a challenge in insuring the required inventory that satisfies each particular case (figure 11).

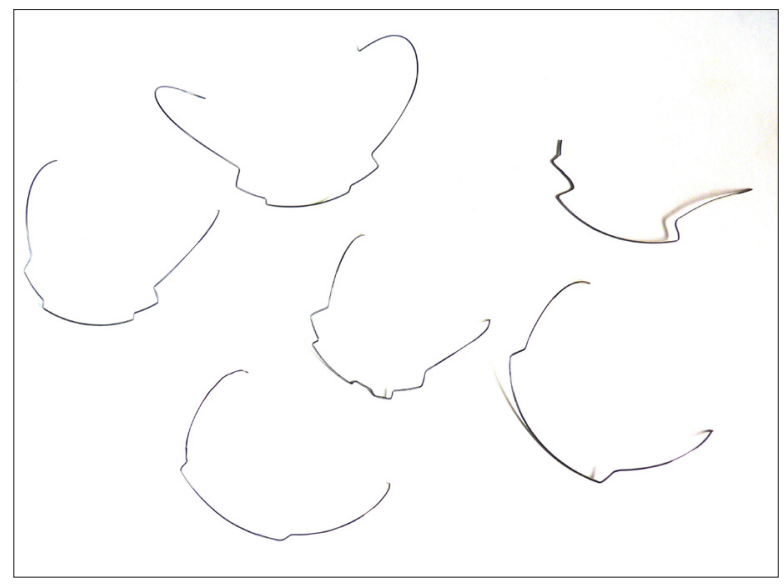

Fig11. Some lingual personalized NiTi archwire configurations.

The difference between lingual and labial techniques in biomechanics, inter-brackets spaces and archwires shape has its own impact on the management, procedures and process of practice of each technique, per se.

The inter-brackets spaces which are less in lingual technique than in labial technique oblige usage of flexible, springy, superelastic, supple and resilient wires.

To avoid the excess force transition into the targeted teeth when inter-brackets distances are low, the
NiTi wires insure physiologic forces with low and continuous force values.

Besides, lingual technique requires peculiar shape of the archwire that consists of three main basic parts: An Anterior Arc, Canines Insets and Posterior Legs (figure 12).

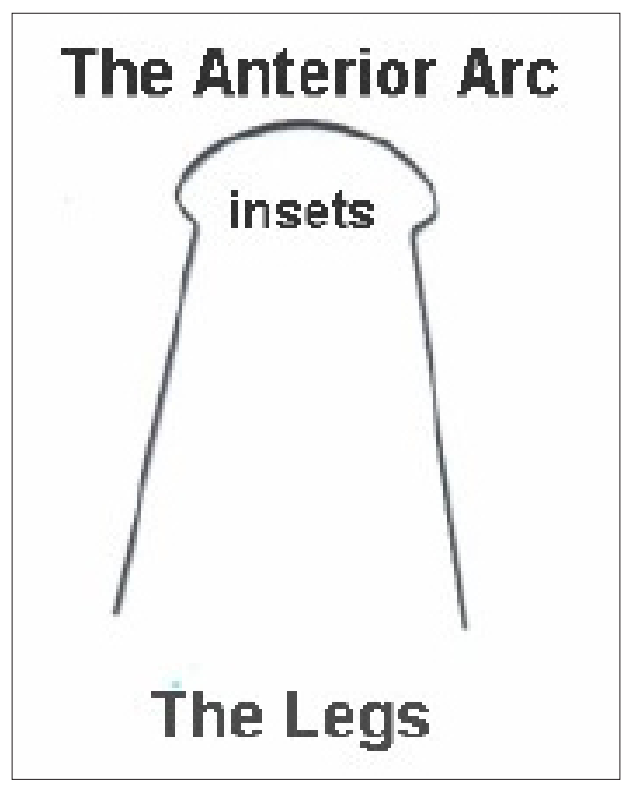

Fig12. The three main parts of the lingual archwire: Anterior Arc, Canines Insets and Posterior Legs.

To enable the clinician to perform successful treatment outcomes it is crucial that orthodontist make the due wires that get along with treatment prerequisites. The so- called personalized NiTi wires satisfy the requirements of such an approach (figure 13) 


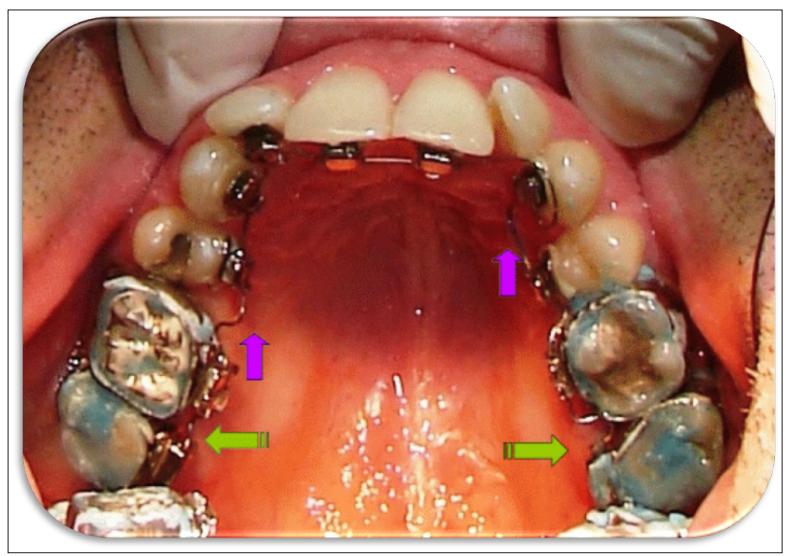

Fig13. Multibends on a NiTi lingual archwire

The DERHT Method insures the clinician to take arches, modifying such wires to be bendable, ductile advantages of the superelasticitc properties of NiTi and shapeable, at the same time (figure 14).

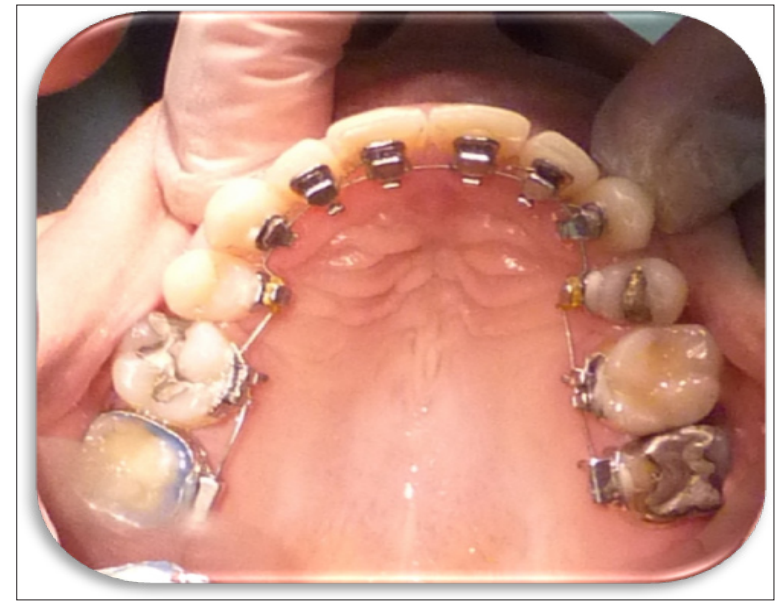

Fig14. Demonstrates a superelastic archwire, with multiple bendings, fulfilled by DERHT method.

Besides, the DERHT technique "with its capability to of low and continuous forces that move teeth even faster superelastic wires modifications" permits the application comparing to other alloys (figure 15).

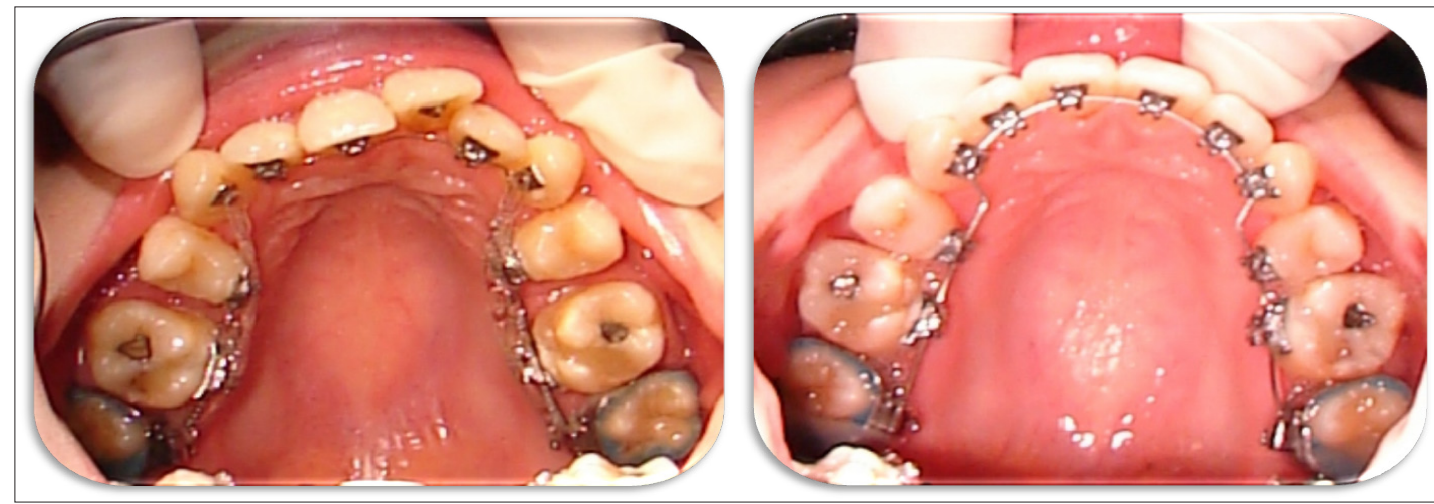

Fig15. The evolution of a lingual case using superelastic wires benefiting of DERHT Method, the case before on left, and after four months on the right side.

\section{Clinical Application}

DERHT Method enables the clinician to get advantage of superelastic properties of the Nickel Titanium
Shape Memory Alloys "SMA" wires in the daily clinical practice. The intelligent usage of this technique helps the orthodontist in insertion of optimum physiologic forces in the daily practice (figure16). 


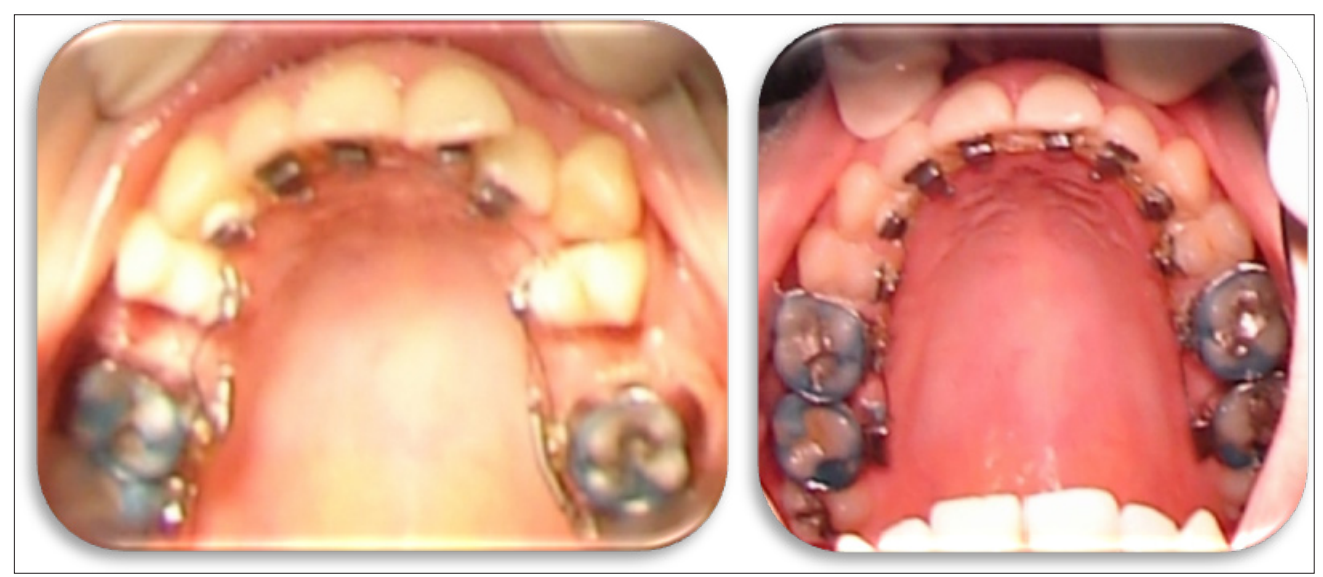

Fig16. A case in which the DERHT method was applied during treatment.

\section{CoNCLUSION}

The DERHT method is helpful in application of physiologic forces by allowing modification of the Shape Memory Alloys SMA wires.

The DERHT method is of paramount importance in lingual technique as it provides the practitioner with the required inventories that get along with each individual case, per se.

Besides, repair, activation and reactivation of the NiTi springs, wires and coils following the DERHT method are worthwhileinincreasing the velocity of orthodontic treatments in a physiologic environment.

The DERHT Method deserves to be widely wellknown especially that this technique is completely safe, secure, harmless and reliable.

\section{REFERENCES}

[1] Graber TM, Vanarsdall RL: Orthodontics: Current Principles and Techniques. Year Book Medical Pub; 2000.

[2] Proffit WR. Contemporary Orthodontics. 2nd ed. St Louis, MO: CV Mosby; 1996:2-16.

[3] Subtelny JD. The soft tissue profile, growth and treatment changes. Angle Orthod. 1961; 31:105-122
[4] Graber, T. M. (1987) Editor's note, American Journal of Dentofacial Othopaedics and Orthodontics, 92, 49.

[5] Drobocky OB, Smith RJ. Changes in facial profile during orthodontic treatment with extraction of four first premolars. Am J Orthod Dentofac Orthop 1989;95:220-30.

[6] Finnoy JP, Wisth PJ, Boe OE. Changes in soft-tissue profile during and after orthodontic treatment. Eur J Orthod 1987;9:68-78.

[7] Roos N. Soft-tissue profile changes in Class II treatment. Am J Orthod 1977;72:165-75.

[8] Burstone CJ. Lip posture and its significance in treatment planning. Am J Orthod 1967;53:262- 84.

[9] Gainsforth B.L. A study of orthodontic anchorage possibilities in basal bone. Am J Orthod Oral Surg 1945;31: 406-417

[10] Melsen B.; Petersen J.K.; Costa A. Zygoma ligatures: an alternative form of maxillary anchorage. J Clin Orthod 1998; 32:154-158

Citation: Mhd. Azhar Ibrahim Kharsa. The DERHT Method Application in Orthodontic Practice. Archives of Dentistry and Oral Health. 2020; 3(2): 03-09

Copyright: (C) 2020 Mhd. Azhar Ibrahim Kharsa. This is an open access article distributed under the Creative Commons Attribution License, which permits unrestricted use, distribution, and reproduction in any medium, provided the original work is properly cited. 